\title{
Conteúdos do judaísmo paulino
}

Edgard Leite

\section{Judaísmos}

É imensa a importância e singularidade de Paulo na história do judaísmo. Seu pensamento foi dotado de uma extraordinária percepção da natureza da herança do povo judeu e do seu destino. A sua capacidade de reunir, para além de toda a aparência, essências diversas na construção de um sistema novo e original não parece ter qualquer paralelo no pensamento religioso judaico antes ou depois dele. Nos tumultuados momentos finais do segundo templo, Paulo realizou uma obra aguda que transcendeu o seu instante e nos alcança dois milênios depois- ainda levantando questões fundamentais sobre a natureza do ser humano e seu destino.

A investigação sobre as fontes de seu pensamento é pesquisa talvez interminável, porque o brilho de sua revelação é íntimo e se situa além de toda tentativa de estabelecer genealogias de idéias. No entanto, podemos afirmar que estão historicamente situadas no judaísmo dos séculos precedentes. Paulo sempre se disse judeu, e toda legitimidade conceitual de seu discurso emanava acima de tudo da tradição literária e cultural judaica. Mas a que judaísmo nos referimos? Como entender as origens do judaísmo de Paulo? Para isso é preciso entender a dinâmica do judaísmo de sua época.

Gabrieli Boccaccini apontou pelo menos quatro perspectivas para o entendimento da natureza do judaísmo do segundo templo e da inserção, nele, do pensamento paulino (BOCCACCINI, 2002). 
A primeira é a de Ed Sanders. Sanders entendeu que o judaísmo do período era um corpo razoavelmente monolítico de doutrinas, caracterizado desde a origem por certos elementos essenciais (SANDERS, 1977, 1985, 1990, 1992). O sistema de Paulo, em seus traços gerais, seria incompatível com os elementos estruturais do judaísmo, restrito este como estava às disposições da tradição e do pacto. Paulo traria, portanto, uma nova essência e se distinguiria dessa tradição, isto é, do judaísmo.

Uma segunda posição é a de Lawrence Schiffman, que entendeu o judaísmo como um permanente desdobrar histórico de experiências em torno de temas comuns, não um "fenômeno monolítico", mas que passou por uma evolução ao longo do tempo (SCHIFFMAN, 1998). O sistema de Paulo seria um desses desdobramentos, que, por suas características, precisou tornar-se uma nova religião para sobreviver, diante do emergente e forte judaísmo farisaico, depois rabínico.

Uma terceira abordagem, a de Shaye Cohen, preferiu entender o judaísmo principalmente como a expressão de uma identidade étnica característica (COHEN, 1987). Estaria essencialmente ligado ao comportamento daqueles que se entendem como judeus, à identidade judaica enquanto tal. Para Cohen, nessa perspectiva, o pensamento de Paulo seria uma variedade de judaísmo. Mas deixou de se-lo quando, supostamente, se distanciou dos elementos étnicos característicos que o identificam.

Uma última abordagem, por fim, é a de Jacob Neusner. Neusner parte da defesa da realidade histórica não de um judaísmo, mas sim de judaísmos, no plural (NEUSNER, 1987, 1994, 1998). Ele sustentou que a experiência religiosa e étnica judaica sempre foi o cenário de divergências entre diversos "sistemas judaicos", expressos em diferentes organizações institucionais conflitantes. Na verdade, segundo Neusner, esse caráter fragmentário é característico da história judaica até os dias de hoje.

A perspectiva de Neusner, segundo Boccaccini, ampliou enormemente as possibilidades de estudo do processo de separação entre judaísmo e cristianismo. E, assim consideramos, do sistema de Paulo. Principalmente porque propiciou um entendimento mais real das controvérsias do judaísmo do segundo templo, enquanto embates entre facções que disputavam a hegemonia política e teológica - mas que existiam separadamente a partir de padrões auto-referenciais.

Assim, o sistema de Paulo deve também ser entendido como judaico. Desenvolvido, como os outros, a partir de linhagens ou tradições identitárias específicas judaicas. De fato, não foi o primeiro ou o único a parecer considerar-se exclusivamente legítimo ou talvez distinto dos demais. Tal perspectiva era corrente desde, pelo menos, a emergência dos samaritanos, ou das 
correntes apocalípticas sectárias. Seria, portanto, um judaísmo entre diversos.

Os manuscritos de Qumran comprovaram a existência de profundas divisões teológicas entre os meios judaicos no período do segundo templo. Que também, às vezes, expressavam rupturas identitárias e políticas. Linhagens teológicas diversas foram, a partir desses textos, visualizadas de forma aproximada. Antes, semelhantes distinções podiam ser percebidas no próprio corpo do Tanach, palco de grandes controvérsias teológicas, mas se percebeu a partir de então que a própria literatura canônica retratava a existência de conflitos institucionais.

Como os outros judaísmos, o sistema de Paulo em suas origens também reivindicava uma origem ancestral e se apresentava como o desenvolvimento de tradições ou a culminância de um processo que tivera início em tempos arcaicos no seio do pacto entre Deus e Abraão. Nisso não era exatamente uma novidade.

Uma das grandes questões dos estudos das origens do cristianismo é, de fato, a investigação das tradições que se entrechocaram nos momentos que precederam e se seguiram à primeira guerra judaica (66 - 73 e.c.). E de onde o sistema paulino retirou sua primeira identidade enquanto judaísmo. Isto é, de onde realmente adquiriu a originalidade que permitiu, depois, a sua caracterização como cristianismo.

A produção de Paulo é a primeira síntese conceitualmente avançada de um sistema que possui singularidade teológica e institucional no âmbito das discussões entre os judaísmos. Ele reivindica esse lugar e sustenta sua argumentação de forma elaborada. Como se sabe, ainda antes dos evangelhos estarem estabelecidos em sua canonicidade, suas cartas já eram consideradas fundamento suficiente da experiência religiosa cristã (ALAND e ALAND, 1995).

\section{Paulo e seus judaísmos.}

Paulo se definia como judeu. "circuncidado ao oitavo dia, da raça de Israel, da tribo de Benjamim, hebreu filho de hebreus, quanto à Lei, fariseu." (Fl, 3:5). O livro dos Atos precisa: "eu sou judeu, de Tarso, na Cilícia" (At, 21:35), criado em Jerusalém, tendo estudado "aos pés de Gamaliel" (At, 22:3).

John Barclay observa que Paulo talvez fosse descendente de judeus levados para a Cilícia como escravos na época das ações de Pompeu na Síria, entre 65-62 a.e.c (BARCLAY, 1996). E sua cidadania romana foi provavel- 
mente herdada do pai ou do avô. Isto demonstra um grau significativo de desenvolvimento e integração dessa comunidade diaspórica, de fala grega.

$\mathrm{O}$ fato de haver estudado em Jerusalém, nos meios farisaicos, em princípio também parece apontar uma vocação espiritual eminente desde sua juventude. No entanto, nos Atos, Paulo explica melhor a natureza dessa vocação, diante do sinédrio em Jerusalém: "sou fariseu, filho de fariseus" (23:6). Isto parece indicar que o farisaísmo, além de um conteúdo teológico específico, continha características identitárias, de dimensões familiares. Isto talvez esclareça melhor o "quanto à Lei, fariseu", isto é, no que diz respeito ao seu judaísmo era daqueles que se organizavam em torno de uma interpretação particular do pacto. Isso pode apontar a grande penetração do pensamento farisaico em círculos diaspóricos, sendo Paulo da Cilícia. Mas principalmente o caráter clânico da experiência farisaica. Uma das explicações possíveis para essa palavra, fariseu, a partir da raiz prsh, é "aqueles que se separam", dos outros judeus, evidentemente.

A força dos fariseus nos meios judaicos no período anterior e posterior a I Guerra é evidente. Eles estão mencionados em todas as fontes relacionadas ao período. Grande parte da literatura neo-testamentária trata de diálogos ou conflitos com eles. Os rabinos do período posterior à revolta de BarKochba (132-135) se julgavam de alguma maneira seus continuadores e honravam suas tradições.

O importante é que os fariseus detinham uma interpretação própria da tradição judaica, não aceita por outros grupos, mas de grande influência. Específicos nesse ponto eram, no entanto, defensores da centralidade de Jerusalém e do Templo. Também estavam associados, em diferentes graus, com o pensamento apocalíptico da época. Pois, como fica bem evidente na discussão de Paulo diante do sinédrio e na tradição rabínica posterior, os fariseus acreditavam nos anjos, na ressurreição dos mortos e talvez em formas específicas de confrontações escatológicas dualistas.

Que o cristianismo, em suas origens, estava intimamente imbricado com o farisaísmo, não é uma afirmação surpreendente. Jesus interage o tempo todo com eles, quer diante de sua força comunitária quer por conta da proximidade teórica. Nem sempre de forma negativa. De fato, os evangelhos trazem uma marca metodológica farisaica, como por exemplo, no permanente recurso à utilização de parábolas. Muitas das quais foram preservadas pela tradição rabínica posterior. Não é estranho, portanto, que Paulo, mesmo envolvido com o "Caminho" (At 9:2), diga ao sinédrio que é "fariseu, filho de fariseu", e não outra coisa. E isso certamente não era uma mentira. Pois essa era sua identidade possível e familiar, naquele momento do processo. 
O mestre de Paulo era Gamaliel. Trata-se, provavelmente, de Gamaliel I, líder fariseu, da primeira geração dos tanaim, os mestres. Atos aparentemente o identifica com "certo fariseu, chamado Gamaliel', que se ergueu em defesa dos cristãos: "se sua obra... se vem de Deus, porém, não poderei destruí-los' (At, 5:38-39). A tradição rabínica o entendia como neto, de sangue ou espiritual, do grande mestre Hillel. Nesse sentido, não é impossível que fosse um dos "prosélitos de Hillel", grupo que reunia o mais avançado dos seguidores convertidos de Hillel e seus dois filhos, Hillel e Gamaliel (NADICH: 208). Como se sabe, um dos aspectos mais significativos de Hillel $o$ velho, era sua atitude doce e receptiva aos prosélitos, em todo diferente da agressividade que caracterizava a relação de seu opositor Shamai com relação ao assunto, inclusive do ponto de vista social. Hillel estendia seu saber não apenas aos ricos, mas também as pobres e de forma muito paciente aos não-judeus (NADICH: 234). A tradição de Hillel, portanto, na qual Paulo se inseria de uma forma ou de outra, era tolerante e inclusiva. $\mathrm{O}$ fato de Paulo ter-se tornado, a partir de determinado momento, um perseguidor dos cristãos, não quer dizer que não tenha sido formado, em algum momento, nessa perspectiva da escola de Hillel, que recebia os não-judeus de forma generosa no âmbito do povo. Se tratasse de um gerim, ou prosélito, não é impossível que Gamaliel pressentisse nos seguidores de Cristo um grupo mais flexível com relação aos não-judeus, realidade que se verificaria no decorrer da pregação paulina.

É evidente, no entanto, e isso repercute em toda literatura cristã antiga, que Paulo, o primeiro teórico cristão, está rompido com a observância da Lei, "segundo os fariseus". Isto é, existe em Paulo a percepção de que o farisaísmo, mesmo o de Hillel, não é capaz de dar conta exclusiva de suas ansiedades espirituais. De qualquer forma, o importante é que, para além da experiência fundadora desse rompimento, a visão na estrada de Damasco, sua percepção daquilo que chama de "Caminho" não é, como nos primeiros apóstolos, apenas fruto de uma sucessão de revelações e prodígios. Mas também é culminância de uma elaboração intelectual complexa. Ele precisava justificar conceitualmente seu movimento de afastamento das tradições farisaicas.

Há, nas epístolas paulinas, uma discussão bastante sofisticada sobre a natureza do judaísmo- do farisaísmo, com mais precisão- e a larga utilização de uma bibliografia de onde são retirados conceitos centrais para uma discussão mais profunda e fundamentada. Isto nos faz levantar uma inevitável questão: Paulo retirava os seus tópicos de discussão teológica apenas do farisaísmo ou tinha acesso a outros documentos, de outros judaísmos da épo$\mathrm{ca}$ ? 
A resposta parece ser a segunda opção. Observemos que Paulo expunha sempre nas sinagogas seus argumentos em termos judaicos, mas não apenas em termos farisaicos. Ele lançava mão de outras abordagens e literatura, que hoje sabemos que eram influentes no período do segundo templo, tanto na Judéia quanto na diáspora. Paulo, sendo judeu fariseu, ao mesmo tempo tomava emprestado elementos de outros judaísmos de seu tempo.

A descoberta dos manuscritos de Qumran revelou uma série de textos que eram tidos por literatura respeitável e sagrada naqueles momentos anteriores a I Guerra. Seja entre movimentos específicos ou, como parece, em círculos mais amplos. O Documento de Damasco, por exemplo, sobreviveu entre grupos judaicos para muito além das conflagrações do limiar da era cristã. Mapear esses elementos é importante para aproximarmo-nos a qual dos judaísmos Paulo se considerava pertencente, de uma forma conceitual, ao menos, no momento em que falava de Jesus Cristo aos seus irmãos, quer aqueles que o eram "segundo a carne" quer aos gentios.

\section{Diálogos entre Paulo e a tradição apocalíptica}

Timothy Lim inventariou alguns pontos razoavelmente consensuais de contato entre a literatura apocalíptica de Qumran e os escritos de Paulo (LIM, 2000). Esses exemplos sugerem a existência tanto de um diálogo direto quanto de um indireto - por exemplo, através de outros textos matrizes ou derivados ou de conceitos que circulavam oralmente entre os judeus. Os temas referidos em ambas as literaturas podem ser compreendidos a partir de contraposições conceituais ou convergências teóricas:

\begin{tabular}{|c|c|c|}
\hline Tema & Paulo & $\begin{array}{c}\text { Manuscritos de } \\
\text { Qumran }\end{array}$ \\
\hline As “obras da Lei". & $\begin{array}{l}\text { "ninguém será justifi- } \\
\text { cado pelas obras da } \\
\text { Lei" (Rm 3:20) "o ho- } \\
\text { mem não se justifica } \\
\text { pelas obras da Lei, mas } \\
\text { pela fé em Jesus Cristo" } \\
\text { (Gl 2:16). }\end{array}$ & $\begin{array}{l}\text { "e ordenou construir para } \\
\text { ele um templo de homem, } \\
\text { para oferecer-lhe nele, } \\
\text { diante dele, obras da Lei" } \\
\text { (4QFlorilegium, col.I:6- } \\
7 \text { ). }\end{array}$ \\
\hline A “nova aliança". & $\begin{array}{l}\text { "tomou o cálice, dizen- } \\
\text { do: 'este cálice é a nova } \\
\text { aliança em meu san- } \\
\text { gue" (1Cor } 11: 25) \text { "foi } \\
\text { ele quem nos tornou }\end{array}$ & $\begin{array}{l}\text { "observar o dia de sábado } \\
\text { segundo as interpretações } \\
\text { exatas, e as festividades e } \\
\text { o dia de jejum, segundo o } \\
\text { que haviam achado os que }\end{array}$ \\
\hline
\end{tabular}




\begin{tabular}{|c|c|c|}
\hline & $\begin{array}{l}\text { aptos para sermos mi- } \\
\text { nistros de uma Aliança } \\
\text { Nova, não da Letra, e } \\
\text { sim do espírito" } 2 \text { Cor } \\
3: 6 \text { ). }\end{array}$ & $\begin{array}{l}\text { entraram na nova aliança } \\
\text { na terra de Damasco, para } \\
\text { apartar as poções santas } \\
\text { segundo sua exata inter- } \\
\text { pretação, para amar cada } \\
\text { qual o seu irmão como a } \\
\text { si mesmo" (Documento } \\
\text { de Damasco VI-18-20). }\end{array}$ \\
\hline $\begin{array}{l}\text { As "Assembléias de } \\
\text { Deus". }\end{array}$ & $\begin{array}{l}\text { "irmãos, vós fostes } \\
\text { imitadores das Igrejas } \\
\text { de Deus que estão na } \\
\text { Judéia" (1Ts 2:14). }\end{array}$ & $\begin{array}{l}\text { "Quando se aproximarem } \\
\text { para o combate, escreve- } \\
\text { rão (...) no sexto estandar- } \\
\text { te: "Assembléia de Deus" } \\
(1 \mathrm{QM} \text { - Rolo da Guerra } \\
\text { IV:9) }\end{array}$ \\
\hline $\begin{array}{l}\text { A "Justiça de } \\
\text { Deus". }\end{array}$ & $\begin{array}{l}\text { "agora, porém, inde- } \\
\text { pendentemente da Lei, } \\
\text { se manifestou a justiça } \\
\text { de Deus, testemunhada } \\
\text { pela Lei e pelos profe- } \\
\text { tas" (Rm 3:21). }\end{array}$ & $\begin{array}{l}\text { "se eu caio em pecado de } \\
\text { carne, na justiça de Deus, } \\
\text { que permanece eterna- } \\
\text { mente, estará o meu juí- } \\
\text { zo" (1QS - Regra da Co- } \\
\text { munidade XI: } 12 \text { ). }\end{array}$ \\
\hline $\begin{array}{l}\text { A comunidade co- } \\
\text { mo Templo. }\end{array}$ & $\begin{array}{l}\text { "nós somos cooperado- } \\
\text { res de Deus e vós sois a } \\
\text { seara de Deus, o edifí- } \\
\text { cio de Deus (1Cor 3:9). } \\
\text { "não sabeis que sois } \\
\text { templo de Deus e que o } \\
\text { espírito de Deus habita } \\
\text { em vós? Se alguém } \\
\text { destrói o templo de } \\
\text { Deus, Deus o destruirá. } \\
\text { Pois o templo de Deus } \\
\text { é santo e este templo } \\
\text { sois vós" (1Cor } 3: 16- \\
17) \text {. }\end{array}$ & $\begin{array}{l}\text { "o conselho da comuni- } \\
\text { dade será estabelecido na } \\
\text { verdade como... uma casa } \\
\text { santa para Israel... será } \\
\text { residência santíssima para } \\
\text { Aarão, com conhecimento } \\
\text { total da aliança da justi- } \\
\text { ça,... e será uma casa de } \\
\text { perfeição e verdade em } \\
\text { Israel” (1QS - Regra da } \\
\text { Comunidade VIII: 1-16). }\end{array}$ \\
\hline $\begin{array}{l}\text { Os "filhos da luz" e } \\
\text { seus caminhos. }\end{array}$ & $\begin{array}{l}\text { "vós, porém, meus } \\
\text { irmãos, não andais em } \\
\text { trevas... pois todos vós } \\
\text { sois filhos da luz" (1Ts } \\
5: 4-5) .\end{array}$ & $\begin{array}{l}\text { "na mão do príncipe das } \\
\text { luzes está o domínio sobre } \\
\text { todos os filhos da justiça, } \\
\text { eles andam por caminhos } \\
\text { de luz e na mão dos anjos } \\
\text { das trevas está todo o }\end{array}$ \\
\hline
\end{tabular}




\begin{tabular}{|c|c|c|}
\hline & & $\begin{array}{l}\text { domínio sobre os filhos da } \\
\text { falsidade, eles andam por } \\
\text { caminhos de trevas. (...) } \\
\text { Porém o Deus de Israel e } \\
\text { o anjo de sua verdade } \\
\text { ajudam todos os filhos da } \\
\text { luz" (1QS - Regra da } \\
\text { Comunidade III: 16-17). }\end{array}$ \\
\hline Lista de vícios. & $\begin{array}{l}\text { "ora, as obras da carne } \\
\text { são manifestas: fornica- } \\
\text { ção, impureza, liberti- } \\
\text { nagem, idolatria, feiti- } \\
\text { çaria, ódio, rixas, ciú- } \\
\text { mes, ira, discussões, } \\
\text { discórdia, divisões, } \\
\text { invejas, bebedeiras, } \\
\text { orgias e coisas seme- } \\
\text { lhantes a estas" (Gl } \\
5: 19-21) \text {. }\end{array}$ & $\begin{array}{l}\text { "porém ao espírito da } \\
\text { falsidade pertence à ava- } \\
\text { reza, a debilidade de mãos } \\
\text { no serviço da justiça, a } \\
\text { impiedade, a mentira, o } \\
\text { orgulho e a altivez de } \\
\text { coração, a falsidade, o } \\
\text { engano, a crueldade, a } \\
\text { hipocrisia, a impaciência, } \\
\text { loucura, ciúmes, obras } \\
\text { abomináveis cometidas } \\
\text { com espírito de luxúria, } \\
\text { caminhos imundos ao } \\
\text { serviço da impureza, lín- } \\
\text { gua blasfemadora, ceguei- } \\
\text { ra de olhos, dureza de } \\
\text { ouvidos, rigidez de nuca, } \\
\text { dureza de coração para } \\
\text { andar por todos os cami- } \\
\text { nhos das trevas e a astúcia } \\
\text { maligna" (1QS - Regra da } \\
\text { Comunidade IV:9-11). }\end{array}$ \\
\hline
\end{tabular}

A trama desse diálogo possui uma dinâmica própria e interessante. Revela a agudeza do pensamento paulino e a profundidade do diálogo que estabelecia no campo teórico com o pensamento apocalíptico da época. Assim, o tema da "obras da Lei" soa como uma discordância de fundo, do mesmo teor da crítica ao farisaísmo, e tem relação com a sua defesa da superioridade da fé sobre as obras. O conceito, em si, pode lhe ter sido sugerido pela sua utilização na pregação apocalíptica. Responde, na sua rejeição, não aos fariseus, mais àqueles influenciados por essa tradição. Isso pode talvez indicar que a polêmica de Paulo com os judaísmos estendia-se também a 
certas perspectivas difundidas pelas correntes que conhecemos a partir de Qumran, que entendia, provavelmente, como atreladas à observância de princípios muito particularistas.

Um pouco diferente é a utilização do conceito de "nova aliança". Esta parece uma reinterpretação da expressão, de todo não farisaica, mas que no contexto do Documento de Damasco implica em algum tipo de retorno a formas ditas "puras" do pacto. Paulo, de certa forma, também trabalhava nesse sentido, embora sua defesa da fé não pudesse permitir um império conceitual das regras, tal como expresso pelos seguidores do "mestre da justiça".

No caso da "assembléia de Deus" talvez se trate de uma convergência. A utilização de uma expressão originalmente de sentido apocalíptico, utilizando-a numa análoga abordagem messiânica. Da mesma maneira o tema da "justiça de Deus" parece ser convergente com a Regra da Comunidade, demonstrando, assim, que Paulo concordava com algumas de suas abordagens do assunto. $\mathrm{O}$ entendimento da comunidade sectária como um templo e seu equacionamento com os seguidores do "caminho" pode expressar, igualmente, uma perspectiva messiânica não desprovida de uma crítica central à desagregação do templo real, o de Jerusalém, com a qual concordava muitos judaísmos no período posterior à rebelião dos macabeus. Isto insere Paulo, antes fariseu, no mundo dos divergentes que tumultuavam o ambiente político da Judéia.

A utilização da expressão "filhos da luz", evidentemente, está em total sintonia com os elementos centrais dualistas da Regra da Comunidade, donde podemos perceber que o "Caminho", de Paulo, é, de certa forma, um caminho que guarda correspondência, ao menos em alguns de seus fundamentos, com o caminho dos grupos dualistas da época.

A tese da origem material dos vícios é conseqüência do dualismo então predominante no pensamento apocalíptico e influente também no farisaísmo. A necessidade de listá-los pode bem ser, por sua vez, fruto da necessidade de estabelecer princípios morais sugerida inicialmente pela Regra da Comunidade ou por semelhantes grupos do período do segundo templo, com variáveis. Paulo assume ou constrói a sua.

O importante e significativo aqui é que Paulo, embora influenciado pelo pensamento apocalíptico, que aparentemente conheceu com razoável proximidade, procura estabelecer uma argumentação própria e original. Ele não é um sectário no rigor da literatura ou das proposições da época. Seu silêncio diante da discussão entre fariseus e saduceus no sinédrio demarca essa singularidade. Nenhum dos dois partidos merece a sua intervenção favorável. 
Também não assume, integralmente, as perspectivas dos outros judaísmos de seu tempo.

O grande momento, no entanto, dessa influência conceitual apocalíptica parece estar na segunda epístola aos coríntios, numa passagem bastante discutida. Isto é, 6:14 - 7:1 (FITZMEYER, 1997). Interpolação ou não, essa passagem guarda uma síntese muito importante da literatura apocalíptica da época. "Que comunhão pode haver entre a luz e as trevas? Que acordo entre Cristo e Belial?... ora, nós é que somos o templo do Deus vivo". O fato de que apenas a literatura apocalíptica se refira ao príncipe das trevas como Belial (por exemplo, 11QMelch II: 13-14) é prova suficiente para atestar que Paulo, ou alguém de seu círculo, conheceu e provavelmente leu e foi influenciado por esses textos.

Não podemos descartar, além do mais, que existisse algum tipo de influência da literatura enóquica que, como se sabe, influenciou em graus variáveis a consciência cristã primitiva. Talvez, principalmente, no que diz respeito à razoável depreciação que essa fazia do papel de Moisés, como Paulo fez, à sua maneira, elevando Abraão (Gl, 3, Rm, 4).

Por fim é interessante e significativo o diálogo entre Paulo e os assim denominados seguidores de João Batista, normalmente associados aos movimentos sectários do deserto, que seriam, em princípio, inseridos na lógica apocalíptica. Existiam na distante cidade de Éfeso, mas nunca tinham ouvido dizer "que haja um Espírito Santo" (At, 19:2). Paulo explica e corrige a sua tradição, inserindo-a facilmente no "Caminho". A conversão dos fariseus ao "Caminho" era assim acompanhada também pela conversão dos movimentos apocalípticos diversos a quem Paulo, como vimos, igualmente pregava em seus próprios termos. Convergindo e divergindo em função de suas necessidades. Paulo integrava assim diferentes judaísmos, buscando sua síntese.

\section{Proposições universalistas anteriores e Paulo}

A singularidade do judaísmo de Paulo, que buscava fontes legitimadoras para além do judaísmo farisaico, pode, no entanto, ter raízes mais profundas. De fato, pelo menos uma de suas afirmações poderia soar intrigante ou vaga antes dos achados literários dos últimos dois séculos ou da ampla divulgação dos manuscritos de Qumran. Mas a partir de então adquiriu consistência documental. Trata-se da sua curta explanação sobre a revelação do Sinai: a Lei, explica, no contexto da discussão de seu significado na história do povo judeu, foi "promulgada por anjos pela mão de um mediador" (G1 3:19). Como se sabe, o texto do Pentateuco, em suas diversas versões, afirma que a legislação sagrada foi revelada por Deus diretamente ao seu mediador, 
isto é, Moisés. A afirmação de que os anjos revelaram a Lei por intermédio de Moisés está contida em outro texto, o Livro dos Jubileus.

Há cópias desse livro em Qumran, e ele já era conhecido através do Documento do Damasco. A igreja etíope o colocava em mesmo grau de sacralidade do Pentateuco. Isso atesta que o livro sobreviveu tanto na tradição judaica medieval quanto em comunidades cristãs que preservaram antigas bibliotecas inspiradas. O importante, no caso, é que a afirmação dissonante de Paulo dá a entender que ele, como os primeiros cristãos, conhecia o Livro dos Jubileus, e o tinha como literatura inspirada. Uma possível citação de

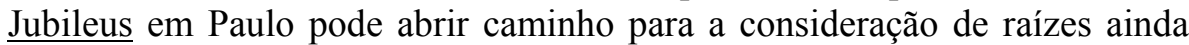
mais profundas de determinadas e mais centrais concepções paulinas. De fato, Jubileus apresenta uma visão particular da história da revelação, como bem perceberam os cristãos dos primeiros momentos do "Caminho".

Jubileus possui vários elementos interessantes. Primeiro, reescreve a linhagem sacerdotal, fazendo-a talvez remontar a Adão, que realizava cerimônias de sacrifício no jardim do Éden, (3:27). Isso em tese generaliza a todo ser humano o acesso ao sacerdócio, provavelmente negando legitimidade exclusiva às genealogias sacerdotais judaicas. Essa perspectiva não é única, pois aparece no terceiro Isaías: "de todas as nações trarão todos os vossos irmãos como uma oferenda a Deus... dentre estes tomarei alguns para sacerdotes e levitas" (66:20-21). O drama histórico judaico envolverá fatalmente a humanidade inteira e o templo de Jerusalém será chamado "casa de oração para todos os povos" (55:7). Assim, o tema parece estar inserido em questões que emergiram após as reformas de Nehemias e Esdras, no período inicial do segundo templo. Jubileu deve ter sido escrito entre 160 e 140 a.e.c. (DAVENPORT, 1971) (VANDERKAM, 1977), o que atesta a continuidade e amadurecimento de uma tradição universalista consistente no judaísmo da época. Cópias do livro foram encontradas em quase todas as cavernas de Qumran.

O tema do acesso universal ao sacerdócio estava presente na escola de Hillel, mas não na mesma perspectiva de Jubileus ou do terceiro Isaías, e era tratado no âmbito das expectativas gentias diante do processo de conversão. O Talmud conta a história do candidato a judeu que procurou Shammai e que pretendia tornar-se judeu e talvez alcançar o sacerdócio. Shammai o expulsou de forma violenta de sua presença. Hillel o recebeu com carinho e atenção, mas explicou que esse cargo não era possível nem ao rei Davi (SHABAT: 31 a). A contradição entre essa afirmativa e a tradição do terceiro Isaías, realça uma diferença farisaica sobre o tema, de capital importância para as perspectivas messiânicas. Já que o sacerdócio universal está diretamente ligado ao advento do Messias. Acreditando no futuro advento da re- 
denção messiânica, os fariseus não estavam aptos, no entanto, sequer a inserir essa argumentação diante dos prosélitos.

Jubileus, além do mais, estabelece novas origens para as festas judaicas, datando-as em períodos anteriores àqueles estabelecidos pela versão deuteronomista da história. Afirma que Noé, por exemplo, observava a festa de Shavuot, (6:17-18) celebração ligada ao recebimento da Lei por Moisés, que teria supostamente ocorrido depois. Estabelece, ainda, que Abraão celebrava tanto Shavuot quanto Sucot (16:15-31). Isso igualmente desvincula as grandes festas judaicas de exclusivas experiências étnicas, dando a elas uma amplitude histórica maior. Dá um desenvolvimento um pouco maior à história de Enoc, mas sustenta, por outro lado, a tese da transgressão de Adão e Eva, tema central das polêmicas que envolviam a tradição de Enoc (COLLINS, 1997:31). Diferenciando-se, por tanto, da tradição enóquica que entendia o mal como exterior ao mundo e nele introduzido pelos "guardiões", os anjos rebelados.

Jubileus aponta o amadurecimento de uma tradição própria, singular, paralela, em sua origem de cunho profético, se considerarmos o terceiro Isaías, que estabelecia um caráter distinto da natureza do povo judeu e da mensagem de Deus que ele portava. Talvez um de seus objetivos fosse harmonizar a historia do povo judeu com a história da humanidade estendendo a todos humanos uma participação no processo de revelação. Nesse sentido o Livro dos Jubileus, que tanta influência parece ter na literatura da época, aprofundava a grandeza histórico-religiosa das leis judaicas, entendendo-as como universais. Estabelecendo, portanto, as bases textuais sagradas para a extensão da mensagem do Deus dos judeus aos não-judeus. Essa tradição consistente configura talvez outro judaísmo que, no seu desenvolvimento, pode estar na raiz do judaísmo de Paulo.

Paulo, de forma às vezes hesitante e não sem contradições, utiliza categorias farisaicas para entender os gentios recebidos no "caminho", já que são eles "filhos de Abraão", benei Abraham (Gl, 3:7), da mesma forma como a tradição rabínica posterior denominará os gerim, os prosélitos. Mas para ele está claro que a ampliação da experiência judaica ao mundo é conseqüência inevitável de uma história que culmina na era messiânica. Assim, muito embora seja oriundo do farisaísmo e tenha dialogado intensamente com a apocalíptica, parece mais que Paulo encarna um judaísmo que, pelo menos desde o terceiro Isaías, no limiar do período do segundo templo, se desenvolveu na profundidade do monoteísmo, levando às últimas conseqüências o universalismo prévio dos profetas. Uma das grandezas de Paulo está em ter culminado essa tradição e se proposto a realizar esse judaísmo não apenas enquanto proposição teórica futura, mas como prática e experiência universal presente. 
Referências

1QM (ROLO DA GUERRA) In MARTINEZ, F. The dead sea scrolls translated. The Qumran texts in English. Leiden, Brill, 1992.

1QS (REGRA DA COMUNIDADE) In MARTINEZ, F. The dead sea scrolls translated. The Qumran texts in English. Leiden, Brill, 1992.

4QFLORILEGIUM In MARTINEZ, F. The dead sea scrolls translated. The Qumran texts in English. Leiden, Brill, 1992.

ALAND, Kurt and ALAND, Barbara: The Text of the New Testament. Eerdmans, 1995.

ATOS DOS APÓSTOLOS, In: A Bíblia de Jerusalém. São Paulo, Paulus, 2004.

BARCLAY, John: Jews in the Mediterranean Diáspora (from Alexander to Trajan) Berkeley, Califórnia, 1996.

BOCCACCINI, Gabriele: Roots of Rabbinic Judaism. Eerdmans, 2002

COHEN, Shaye: From the maccabees to the mishnah. Westminster, 1987.

COLLINS, J. Apocalypticism in the dead Sea Scrolls. London Routledge, 1997.

DAVENPORT, G.L. The eschatology of the book of jubilees. Studia PostBiblica, 20. Leiden, 1971.

DOCUMENTO DE DAMASCO In MARTINEZ, F. The dead sea scrolls translated. The Qumran texts in English. Leiden, Brill, 1992.

FILIPENSES, In: A Bíblia de Jerusalém. São Paulo, Paulus, 2004

FITZMYER, Joseph .A. "Qumran and the Interpolated Paragraph in 2 Cor 6:14 - 7:1 in FITZMYER, Joseph: Essays on the Semitic Background of the New Testament. Vol. 1 Eerdmans, 1997.

GALATAS In: A Bíblia de Jerusalém. São Paulo, Paulus, 2004

LIM, Timothy H. "Letters of Paul" in SCHIFFMAN, Lawrence H. and VANDERKAM, James C.: Encyclopedia of the Dead Sea Scrolls. Oxford, 2000.

NADICH, Judah: The Legends of the Rabbis, vol.I. London, Aronson, 1994.

NEUSNER, Jacob, The Four Stages of Rabbinic Judaism. London, Routledge, 1998.

NEUSNER, Jacob: The Judaism the Rabbis Take for Granted. Atlanta, Scholars, 1994. NEUSNER, Jacob, Green, William Scott and Frerichs, Ernest S. Judaims and Their Messiahs at the Turn of the Christian Era. Cambridge, Cambridge University Press, 1987. 
PRIMEIRA AOS CORÍNTIOS In: A Bíblia de Jerusalém. São Paulo, Paulus, 2004

PRIMEIRA AOS TESSALONICENSES In: A Bíblia de Jerusalém. São Paulo, Paulus, 2004

ROMANOS, In: A Bíblia de Jerusalém. São Paulo, Paulus, 2004

SANDERS, E. P.: Jesus and Judaism, Philadelphia, Fortress, 1985.

SANDERS, E. P.: Jewish Law from Jesus to the Mishnah, Philadelphia, Trinity, 1990.

SANDERS, E. P.: Judaism, Practice and Belief, 63bce-66 ce Philadelphia, Trinity, 1992.

SANDERS, E. P.: Paul and Palestinian Judaism. Philadelphia, Fortress, 1977.

SHABAT in EPSTEIN, R. Dr. I. (Ed.): Hebrew-English Edition of the Babylonian Talmud. London, Soncino Press, 1990.

SCHIFFMAN, L: Texts and Traditions: a Source Reader for the Study of Second Temple and Rabbinic Judaism. Hoboken, Ktav, 1998.

SEGUNDA AOS CORÍNTIOS In: A Bíblia de Jerusalém. São Paulo, Paulus, 2004

VANDERKAM, J. C. Textual and historical studies in the book of Jubilees. Harvard Semitic Monographs, 14, 1977.

Edgard Leite

Professor Dr. Adjunto de História das Religiões, UERJ - UNIRIO Membro do Conselho Acadêmico do Centro de História e Cultura Judaica Integrante da Bnai Brith edleiteneto@yahoo.com.br 